\title{
The Drosophila P68 RNA helicase regulates transcriptional deactivation by promoting RNA release from chromatin
}

\author{
Michael Buszczak and Allan C. Spradling ${ }^{1}$ \\ Howard Hughes Laboratories/Embryology Department, Carnegie Institution of Washington, \\ Baltimore, Maryland 21218, USA
}

Terminating a gene's activity requires that pre-existing transcripts be matured or destroyed and that the local chromatin structure be returned to an inactive configuration. Here we show that the Drosophila homolog of the mammalian P68 RNA helicase plays a novel role in RNA export and gene deactivation. p68 mutations phenotypically resemble mutations in small bristles $(s b r)$, the Drosophila homolog of the human mRNA export factor NXF1. Full-length hsp 70 mRNA accumulates in the nucleus near its sites of transcription following heat shock of $p 68$ homozygotes, and hsp 70 gene shutdown is delayed. Unstressed mutant larvae show similar defects in transcript accumulation and gene repression at diverse loci, and we find that $p 68$ mutations are allelic to Lighten-up, a known suppressor of position effect variegation. Our observations reveal a strong connection between transcript clearance and gene repression. P68 may be needed to rapidly remove transcripts from a gene before its activity can be shut down and its chromatin reset to an inactive state.

[Keywords: p68; RNA helicase; transcription; RNA export]

Received November 28, 2005; revised version accepted February 7, 2006.

Programmed gene shutoff plays an essential and complementary role to gene induction during the development of metazoan organisms, yet the mechanisms governing transcriptional deactivation are less well understood. Active and quiescent genes differ in at least two major respects. First, the organization and modification state of chromatin becomes specialized for gene activity (for review, see Henikoff and Ahmad 2005). Second, active loci contain immature transcripts coated with protein complexes that mediate transcript initiation, elongation, termination, and processing (for review, see Aguilera 2005). All the processes required to generate and export mature transcripts appear to be closely connected and coregulated (for review, see Reed 2003; Vinciguerra and Stutz 2004). Hence, multiple protein complexes and their associated nascent transcripts must be appropriately disposed of when a gene is shut off.

Differences in active versus inactive gene chromatin have been well characterized using the stress-inducible Drosophila hsp70 heat-shock genes. Upon heat shock, the transcription factor Heat-Shock Factor (HSF) forms trimers and binds to Heat-Shock Response Elements (HSEs) within response gene promoters (Wu et al. 1987; Westwood and Wu 1993). Recruitment of HSF to DNA results in phosphorylation of histone $\mathrm{H} 3$ on Ser10 at those sites (Nowak and Corces 2000). Moreover, the

${ }^{1}$ Corresponding author.

E-MAIL spradling@ciwemb.edu; FAX (410) 243-6311.

Article published online ahead of print. Article and publication date are at http://www.genesdev.org/cgi/doi/10.1101/gad.1396306.
TAC1 complex acetylates histone $\mathrm{H} 3$, and this activity is essential for robust expression of heat-shock response genes (Smith et al. 2004). Both histone phosphorylation and acetylation coincide with the recruitment of elongation factors, such as Spt6, to the Pol II complex (Andrulis et al. 2000). Elongation proteins, along with TFIIS, promote Pol II release from the promoter and productive polymerization of stress-induced transcripts during the duration of the heat shock (Adelman et al. 2005). In addition, chromatin-bound poly(ADP-ribose) polymerase (PARP) at heat-shock response loci is modified with long poly(ADP-ribose) chains upon induction, and this process is essential for chromatin loosening and transcript production (Tulin and Spradling 2003). When the hsp70 genes shut down, these changes in histone modification and poly(ADP-ribose) accumulation are reversed.

Mechanisms used to export RNAs away from transcription sites and to proofread their structure (for review, see Fasken and Corbett 2005) are likely to facilitate transcript removal concomitant with gene shutdown. In yeast, finished transcripts accumulate at their sites of synthesis when export is defective (Jensen et al. 2001). Interestingly, the yeast Rrp6p exoribonuclease, a component of the RNA processing and proofreading complex known as the exosome, is essential for transcript accumulation (Hilleren et al. 2001), suggesting that the exosome plays a role in signaling transcript release from the vicinity of the gene. The multiple subunits of the Drosophila exosome strongly resemble their yeast counterparts, and associate with Spt6 on actively transcribed genes, including hsp70 genes (Andrulis et al. 2002). How- 
ever, the function of the exosome in transcript export in Drosophila has not yet been tested.

Studies of RNA export in Drosophila suggest that the pathway has been highly conserved. Close homologs of the "export adaptor" proteins Y14 (Tsunagi) (Mohr et al. 2001), Aly/REF, and UAP56/BAT1 (Gatfield et al. 2001; Gatfield and Izaurralde 2002) and the "export receptor" components P15 and NXF1 (Herold et al. 2001; Wilkie et al. 2001) are also found within the Drosophila genome. The yeast THO-TREX complex is thought to mediate the association of some transcripts with the export receptor (Jimeno et al. 2002), and homologs of some but not all of these proteins are present in flies. The UAP56 RNA helicase encoded by the Hel25E gene and the NXF1 homolog encoded by small bristles ( $s b r$ ) are essential for the export of an estimated $75 \%$ of Drosophila mRNAs in cultured cells (Gatfield et al. 2001; Herold et al. 2003), but Aly/REF is not essential for export of bulk RNA (Gatfield and Izaurralde 2002). When Hel25E is knocked down using RNA interference (RNAi), poly(A)-containing RNA is retained in the nucleus and expression of heat-shock proteins is blocked. RNAi inactivation of several THO components also disrupts the export of heat-shock transcripts, but affects only $\sim 20 \%$ of genes overall (Rehwinkel et al. 2004). Strong alleles of both Hel25E and sbr are lethal; animals bearing weaker sbr alleles survive to adulthood, but have abnormally thin thoracic brisles, and exhibit female sterility (Wilkie et al. 2001; Golubkova et al. 2004).

A common feature shared by many of the ribonucleoprotein (RNP) complexes at transcription sites is the inclusion of DEAD-box RNA helicases. DEAD-box RNA helicases unwind RNA:RNA and RNA:DNA duplexes (Pause and Sonenberg 1992; Huang and Liu 2002), disrupt RNA-protein interactions (Jankowsky et al. 2001), and have been implicated in rRNA processing, transcription, pre-RNA splicing, and mRNA transport (Rocak and Linder 2004). For example, the helicase Sub2p, the yeast homolog of Hel25E, functions in splicing, plays a pivotal role in RNA export by facilitating transcript binding to the export receptor, and also interacts with the THO complex (Strasser et al. 2002). P68 is another conserved RNA helicase that has been implicated in multiple functions within the nucleus. Mammalian P68 acts during splicing (Lin et al. 2005) but also functions in transcriptional repression (Wilson et al. 2004).

There are indications that disruption of gene processing can influence gene activity and genomic stability (Manley 2002). Some processing factors in yeast have been shown to interact with basal transcription machinery (Kwek et al. 2002; Estruch and Cole 2003) or chromatin-modifying components (Rodriguez-Navarro et al. 2004). When RNA export is perturbed, recombination is enhanced, and this has been ascribed to the disruptive effects of RNA:DNA hybrids that form at the affected loci (Huertas and Aguilera 2003). In metazoan organisms, it remains unknown if RNA processing and export processes can influence gene activity.

Here, we report that in Drosophila, the P68 RNA helicase participates in transporting transcripts away from their sites of synthesis and in shutting off genes. Flies mutant for $p 68$ resemble sbr mutants, and retain completed mRNAs at their transcription sites. Unexpectedly, these defects in export are associated with problems in shutting off active genes. Our findings suggest that a fundamental connection exists between transcript clearance and gene repression.

\section{Results}

Drosophila P68 is found at sites of active trancription

Gene deactivation may require that nascent transcripts be cleared from transcription sites and exported or degraded before the chromatin within the region can be reset to a fully inactive state. To identify RNA processing and export factors that might be involved in transcriptional repression, endogenous Drosophila gene products were tagged with EGFP using a previously described P-element-based protein trap screening technique (Morin et al. 2001). One line from our collection, CB02119, was of particular interest because the EGFP fusion protein localized to chromosomal sites of active transcription including the nucleolus and polytene chromosome puffs (Fig. 1A; data not shown). The sequence of the flanking genomic DNA indicated that $C B 02119$ was inserted within an intron of Rm62 (Fig. 1B), the Drosophila ortholog of the p68 RNA helicase, a protein that in mammals functions in RNA processing (Bates et al. 2005; Lin et al. 2005). Multiple differentially spliced transcripts of this gene encode proteins of $\sim 63 \mathrm{kDa}$ as well as one isoform of $79 \mathrm{kDa}$ (Fig. 1B; FlyBase). Sequencing of RT-PCR-amplified transcripts from CB02119 confirmed that this strain expresses an in-frame fusion between EGFP and the p68-RA isoform (Fig. 1B).

To characterize P68 expression, we generated a polyclonal antibody directed against an $\mathrm{N}$-terminal region common to all isoforms. By Western blot, this antibody specifically recognizes an abundant band of $\sim 63 \mathrm{kDa}$ as expected in wild-type ovary extracts (Fig. 1F). Costaining CB02119 heterozygous ovaries and larval tissue with anti-P68 and anti-GFP antibodies showed that the EGFP fusion protein displayed a virtually identical expression pattern and subcellular localization as the endogenous proteins (data not shown). In addition, double labeling of polytene chromosome squashes using both anti-P68 antibodies and anti-P11, a monoclonal antibody that recognizes the Hrb87F hnRNP protein that has previously been shown to localize to puffs (Reim et al. 1999), revealed an almost perfect overlap, confirming the chromosomal localization of P68 deduced from CB02119 expression (Fig. 1C). The localization of P68 to chromosomal puffs and the fact that mammalian P68 modulates both transcription and pre-mRNA splicing suggested that Drosophila p68 might also play a role in RNA production.

p68 mutant phenotypes are similar to RNA export factor mutations

To test the hypothesis that $p 68$ mediates some aspect of RNA metabolism at transcription sites, we sought to 


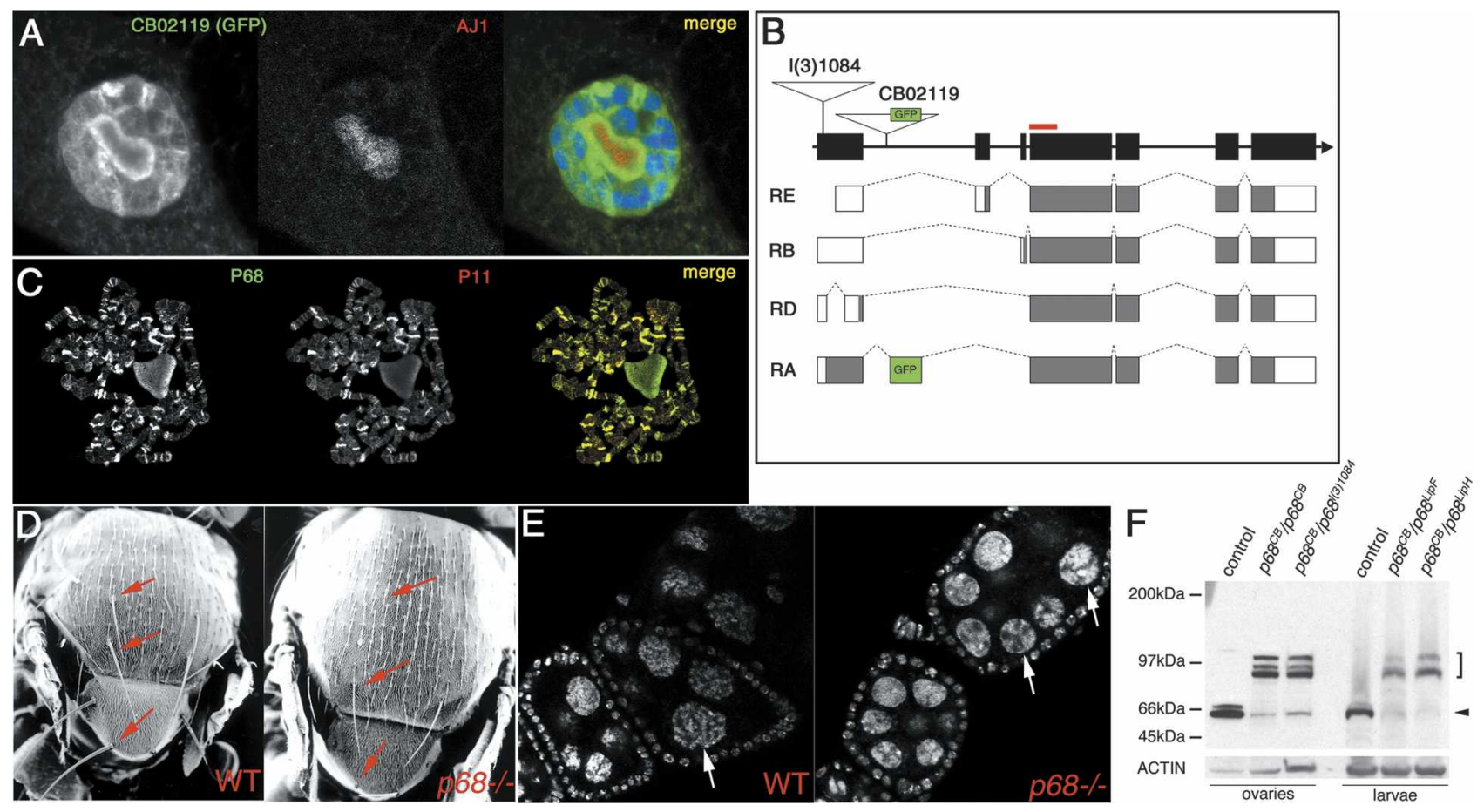

Figure 1. Drosophila P68 localizes to specific sites on polytene chromosomes. (A) A CB02119/TM3 third instar larval salivary gland cell in which the EGFP-P68 fusion protein (green) localizes around the rim of the nucleolus (marked by anti-AJ1 staining in red) and with specific bands on polytene chromosomes (DNA marked in blue). (B) p68 gene and transcript structure. The p68 gene (solid line) encodes at least six different normal transcripts (four are shown); the RA transcript fuses to the EGFP exon (green) carried by CB02119. The untranslated region (white), coding regions (gray), and insertion alleles (triangles) are also shown. The red line above the gene structure represents the $\mathrm{N}$-terminal region against which the anti-P68 polyclonal antibody was generated. $(C)$ Wild-type polytene chromosomes stained with anti-P11 (red) and anti-P68 (green) antibodies. Endogenous P68 is indistinguishable from CB02119 EGFP expression, and colocalizes with P11 on chromosomal puffs and other secondary loci. $(D)$ Scanning electron micrographs showing normal dorsocentral and scutellar bristles (arrows) from wild type that are reduced or missing in an CB02119/1(3)01084 adult. (E) Wild-type and CB02119/1(3)01084 stage 5-7 ovarian follicles stained with DAPI. The nurse cell chromatin in p68 mutant follicles frequently fails to disperse as in wild type (cf. arrows in wild-type [WT] and $p 68^{-/-}$samples). (F) Western blot of ovarian and larval extracts probed with anti-P68 antibody. In lanes corresponding to control ovarian and larval samples, the anti-P68 antibody crossreacts with proteins of the expected molecular weights for the endogenous P68 isoforms (arrowhead). The CB02119 allele expresses a small amount of normal P68. In addition, other bands corresponding to proteins with the mobility of endogenous P68 plus EGFP (bracket) are observed. The 1(3)01084, $\mathrm{Lip}^{F}$, and $\mathrm{Lip}^{H}$ alleles are inferred to express very little P68. Anti-ACTIN antibodies were used for the loading control.

identify mutants that disrupt p68 function. The Drosophila genome project (Spradling et al. 1999) had previously generated several P-element insertions within the $5^{\prime}$ region of $p 68$ that caused lethality, including 1(3)01084 (Fig. 1B). The suggestion from Spradling et al. (1999) that the 1(3)01084 lethal complementation group is allelic to a previously identified mutant, Lighten-up (Lip) (Csink et al. 1994), was verified by characterizing heteroallelic combinations of these alleles (Table 1). Moreover, these mutants expressed reduced amounts of endogenous P68 on Western blots (Fig. 1F).

Viable $p 68$ mutant flies frequently had small, thin, or missing dorso-central and scutellar bristles (Fig. 1D). Both CB02119 homozygous and CB02119/1(3)01084 transheterozygous females were also sterile. The nurse cell chromosomes of CB02119/1(3)01084 mutant follicles failed to disperse during the fifth endocycle (Fig. 1E) as in wild type (Dej and Spradling 1999), and these follicles degenerated by stage 8 (data not shown). These phenotypic effects strongly resemble those caused by mutations in sbr, which encodes a Drosophila ortholog of the mammalian RNA export receptor subunit NXF1 (Gatfield et al. 2001; Herold et al. 2003). The bristle defects in $s b r$ and $p 68$ adults are indistinguishable, and like

Table 1. Complementation grid of p68 alleles

\begin{tabular}{|c|c|c|c|c|c|c|c|}
\hline & СB02119 & $1(3) 01084$ & $\operatorname{Lip}^{\mathrm{D}}$ & $\operatorname{Lip}^{\mathrm{E}}$ & $\operatorname{Lip}^{F}$ & $\operatorname{Lip}^{\mathrm{H}}$ & $\operatorname{Lip}^{\mathrm{K}}$ \\
\hline СB02119 & Sterile & Sterile/bristle & Viable & Viable & Lethal & Lethal & Lethal \\
\hline 1(3)01084 & Sterile/bristle & Lethal & Lethal & Viable & Lethal & Lethal & Lethal \\
\hline
\end{tabular}


the viable $p 68$ mutants, adults bearing conditional sbr alleles are female sterile at the restrictive temperature and undergo follicle degeneration (Wilkie et al. 2001; Golubkova et al. 2004). These similarities between the viable p68 and sbr phenotypes suggested that P68 might function in RNA export.

\section{Loss of p68 results in accumulation of RNA at transcription sites}

Since the inducible expression of $h s p 70$ has been widely used to characterize defects in RNA export, we tested whether altering $p 68$ activity affects the release of $h s p 70$ RNA from its transcription sites following heat shock. Wild-type and $p 68$ mutant third instar larvae were heatshocked for $20 \mathrm{~min}$, and hsp $70 \mathrm{mRNA}$ was localized in salivary glands from these animals using fluorescent in situ hybridization (FISH). In control animals, hsp70 mRNA was already abundant in the cell cytoplasm immediately after heat shock (AHS), and was also present in the nucleoplasm and at foci that corresponded to its sites of transcription at $87 \mathrm{C}$ and $87 \mathrm{~A}$ (Fig. 2A). In contrast, p68 mutant cells displayed almost no hsp70 RNA in the cytoplasm or nucleoplasm at this time (Fig. 2B). Instead most of the RNA was still found at its sites of synthesis. p68 mutants continued to exhibit transport defects $30 \mathrm{~min}$ after returning to normal temperature (data not shown). The slow movement of hsp70 RNA into the cytoplasm and its buildup at $h s p 70$ gene loci indicates that P68 affects RNA clearance.

To rule out the possibility that P68 has a preferential role in removing heat shock gene transcripts, or transcripts from genes lacking introns, we pulse-labeled unstressed wild-type and mutant salivary glands with $\mathrm{Br}$ UTP and then treated them with $\alpha$-amanitin to stop transcription (Fig. 2C,D). Tissue was then incubated for a further period to allow nascent RNAs time to be transported away from their transcription sites. Control cells displayed diffuse nucleoplasmic and cytoplasmic staining of Br-UTP-labeled transcripts after $\alpha$-amanitin treatment, reflecting the movement of RNA away from chromatin and out of the nucleus (Fig. 2C). In contrast, labeled RNA in CB02119/ $\mathrm{Lip}^{F}$ cells remained associated with the chromosomes in a tight banded pattern, indicating that many loci were affected (Fig. 2D). Little if any labeled RNA was detected in the cytoplasm of mutant cells. These data are consistent with the results obtained for hsp70 genes and demonstrate that reduced P68 activity disrupts RNA transport away from multiple transcription sites.

\section{Loss of p68 results in redistribution of export factors within nuclei}

If $\mathrm{P} 68$ functions just upstream or within the RNA export pathway, disruption of its action might alter the nuclear distribution of known RNA export components. In normal cells, RNA export proteins shuttle between transcription sites and nuclear pores. If P68 function occurs preferentially at genes before their newly made transcripts begin to move toward nuclear pores, as our ex-

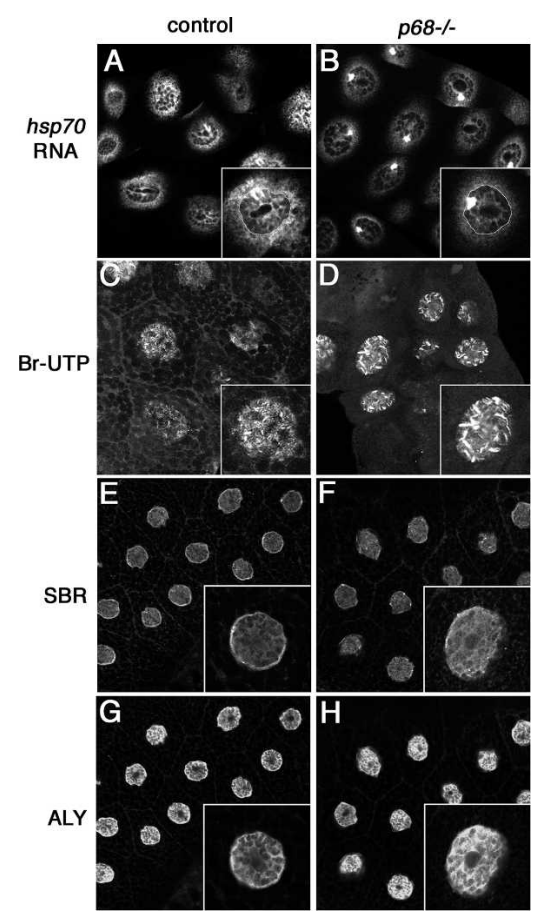

Figure 2. $p 68$ mutants display RNA export defects. $(A, B)$ Control $(A)$ and $C B 02119 / \operatorname{Lip}^{F}(B)$ transheterozygotes labeled for hsp70 RNA immediately after a 20-min heat shock. The edge of representative nuclei is outlined in white (boxes). p68 mutant salivary glands have less cytoplasmic hsp70 RNA and qualitatively higher levels of hsp70 RNA at transcription sites. $(C, D)$ Control $(C)$ and $C B 02119 / \operatorname{Lip}^{F}(D)$ salivary glands labeled with Br-UTP. Control cells exhibit cytoplasmic staining and punctuate nuclear Br-UTP staining, whereas p68 mutant salivary glands display robust Br-UTP labeling on polytene chromosomal bands. Little signal was observed in the cytoplasm of mutant cells. $(E-H)$ Control $(E, G)$ and CB02119/Lip ${ }^{F}(F, H)$ salivary gland cells stained with anti-SBR (NXF1) antibodies $(E, F)$ or anti-ALY (REF1) antibodies $(G, H)$. SBR and ALY are found along the nuclear periphery and in the nucleoplasm of control cells. In p68 mutant cells, their distribution is changed, and both export factors accumulate in the nuclear interior.

periments suggest, then other export factors might also accumulate around sites of active RNA production in p68 mutants.

We tested these expectations by examining the cellular location of two previously characterized export proteins, SBR (NXF1) (Herold et al. 2001) and Aly(REF1) (Rodrigues et al. 2001). Control and p68 ${ }^{\text {CBO2119/LipF }}$ mutant salivary glands were stained with anti-SBR antibodies to determine whether reducing $p 68$ activity changed the normal distribution of this export factor (Fig. 2E,F). In control samples, SBR localized along the rim of the nucleus and in the nucleoplasm, as expected. However in p68 mutant cells, SBR levels decreased along the nuclear rim and increased within the nucleoplasm (Fig. 2F). Similar results were observed using antibodies to the Drosophila REF export factor (Fig. 2G,H). These changes in export factor distribution suggest that P68 functions upstream or in conjunction with other export factors at sites of gene transcription. 
p68 mutants delay heat shock gene deactivation

Retarding RNA transport out of the nucleus would be expected to delay translation of the affected mRNAs. Therefore to further verify that P68 functions in RNA export, we studied the time course of HSP70 protein production following heat shock. Larvae were heat-shocked for $30 \mathrm{~min}$ and allowed to recover for up to $6 \mathrm{~h}$, during which time samples were removed and analyzed for HSP70 protein and RNA production. In control larvae, HSP70 was readily detected during the 30-min heat shock (Fig. 3A). HSP70 protein levels reached a maximum $2 \mathrm{~h}$ later and then began to slowly fall, in accordance with previously described kinetics of the heat shock response (DiDomenico et al. 1982a). CB02119/ $\mathrm{Lip}^{F}$ larvae showed a very different pattern of HSP70 protein production. Detectable amounts of protein did not appear by the end of the 30-min heat shock, consistent with the strong reduction of hsp 70 mRNA in the cytoplasm of the mutant cells. Interestingly, however, similar amounts of HSP70 protein did eventually accumulate, beginning $2 \mathrm{~h}$ after the start of the recovery period. Therefore, many of the hsp 70 transcripts that accumulate near their transcription sites must be functional, eventually reach the cytoplasm, and be translated despite the delay. As a result, at 4 and $6 \mathrm{~h}$ AHS, the mutant animals contained higher levels of HSP70 than the controls.

To investigate the structure and fate of the transcripts that accumulate at transcription sites in p68 mutants, we analyzed hsp70 mRNA by Northern blot analysis (Fig. 3B). As above, CB02119/ Lip $^{F}$ larvae were heatshocked for $30 \mathrm{~min}$ and allowed to recover for up to $6 \mathrm{~h}$, during which timed samples were removed and analyzed for RNA production. As expected, control larvae accumulated high levels of polyadenylated hsp70 mRNA only for a short period following the heat shock. Two hours later, hsp70 transcripts had dropped to near background levels, and no transcripts could be detected at $4 \mathrm{~h}$, reflecting the known rapid shutoff of hsp 70 transcription and turnover of $h s p 70 \mathrm{mRNA}$ in the hours following a 30-min heat shock (DiDomenico et al. 1982b). The hsp70 mRNA in the CB02119/ Lip $^{F}$ mutant larvae immediately after heat shock was indistinguishable in size and amount from the control RNA (Fig. 3B), despite the fact that it remains predominantly at its sites of transcription and is not translated. The large amount of transcript and absence of shorter forms strongly argue that hsp 70 transcription, cleavage, and polyadenylation are normal in p68 mutants. We cannot rule out the existence of small changes in poly(A) length, however. Unlike wild type, in p68 mutants some of these mature transcripts persisted for up to $4 \mathrm{~h}$ AHS, in contrast to controls. Thus, the delayed export and abnormal persistence of mature hsp70 mRNA probably explains the kinetics of HSP70 expression in the mutant animals.

To further rule out the possibility that reduction of p68 function disrupts some aspect of normal transcription, and to look for defects in RNA splicing, we carried out additional Northern blot experiments using a 10-min heat shock and analyzed both hsp70 and hsp83 RNA at

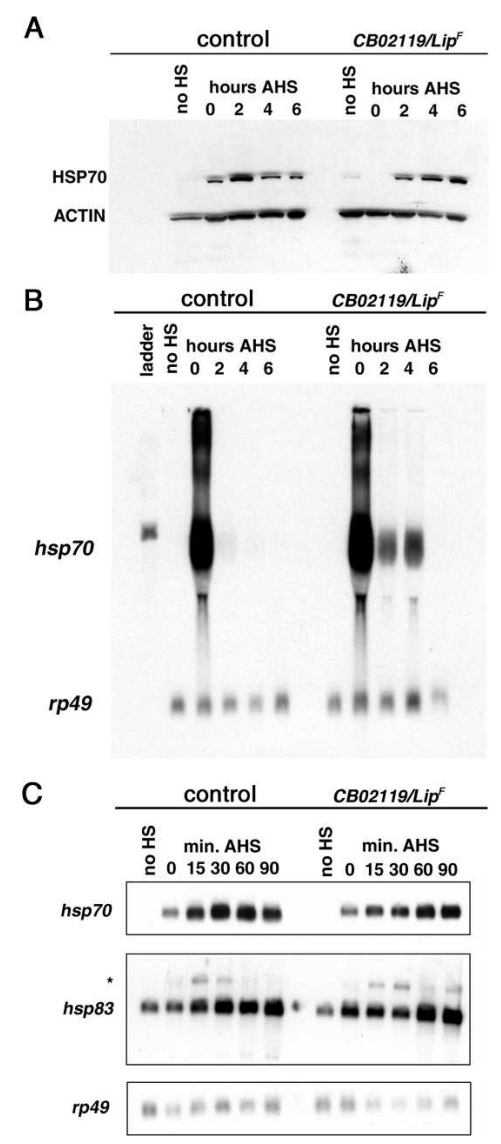

Figure 3. p68 mutants exhibit both delays in translation and prolonged gene transcription. $(A)$ Western blot analysis of larval extracts probed with anti-HSP70 and anti-ACTIN antibodies. No heat shock (no HS) represents non-heat-shocked controls. Animals were heat-shocked for $30 \mathrm{~min}$ and allowed to recover for the indicated times after heat shock. HSP70 expression is detectable at the 0 -h time point in the control sample, increased up to $2 \mathrm{~h}$ AHS, and then begins to decline. In mutant samples, HSP70 expression is undetectable immediately after a $30-\mathrm{min}$ heat shock ( $0 \mathrm{~h}$ AHS), is first detected at the 2-h AHS time point, and continues to increase for up to $6 \mathrm{~h}$ AHS. $(B)$ Northern blot analysis of heat-shocked animals. Control and CB02119/ Lip $^{F}$ mutant animals were heat-shocked for $30 \mathrm{~min}$ and allowed to recover for up to $6 \mathrm{~h}$. Controls displayed robust expression of hsp70 in response to heat shock that rapidly declined upon removal from heat shock. CB02119/Lip ${ }^{F}$ mutant samples continued to express $h s p 70$ for up to $4 \mathrm{~h}$ after removal from heat shock. (C) Control and CB02119/Lip ${ }^{F}$ mutant animals were heatshocked (HS) for $10 \mathrm{~min}$ and allowed to recover for the indicated times. Total RNA was isolated, separated on a formaldehyde gel, and probed for $h s p 70, h s p 83$, and rp49 RNA. Control and p68 mutant samples do not display any overt differences in the timing or expression levels of $h s p 70$ and $h s p 83$ during the initial response to a short heat shock. Furthermore, the amount of unspliced hsp83 (asterisk) appears to be similar in control and p68 mutant samples, suggesting that loss of $p 68$ does not affect RNA processing.

frequent intervals. Drosophila hsp83 is a constitutive gene with one intron whose transcription is strongly induced by heat shock. As we found in our previous experiments, hsp70 RNA was induced in $p 68^{C B 02119 / L i p F}$ 
mutant samples at similar levels to wild-type animals (after normalizing to the rp49 controls), but persisted longer during recovery (Fig. 3C). hsp83 mRNA followed a very similar pattern. Comparable amounts of normalsized and polyadenylated hsp 83 transcripts were made initially in the $p 68^{\text {CBO2119/LipF }}$ mutants and controls, while higher amounts persisted 60 and 90 min AHS.

The fact that we could observe a band at the expected size of unspliced hsp83 (Fig. 3C, asterisk) allowed the effects of $p 68$ mutation on splicing to be addressed. The intensity of unspliced hsp83 RNA was no greater in the mutant than in controls during the initial $15 \mathrm{~min}$, indicating that splicing was not significantly compromised. Unspliced hsp83 transcript in control animals was detected 15 and 30 min AHS, when hsp83 transcription is likely to be ongoing, but was not detected at later times when expression is presumably shut off. In p68CBO2119/LipF mutants beginning at $\sim 30$ min AHS, the amount of unspliced hsp83 transcript was slightly elevated compared with controls, and could still be detected 90 min AHS. However, the small increase and the persistence of a pool of intron-containing hsp83 transcript probably just reflects continued hsp83 transcription in the mutant compared with wild-type animals (see below). Our results argue that transcription, splicing, cleavage, and polyadenylation of the $h s p 70$ and $h s p 83$ genes still occurs normally when $p 68$ levels are reduced, but suggest that in addition to retarding RNA export, defects in $p 68$ increase the time required to shut off the transcription of these genes.

\section{p68 mutation impairs gene shutdown after heat shock}

The observation that $p 68$ mutants express heat shock transcripts for a prolonged period is interesting in light of the aforementioned finding that p68 is allelic to the Lip locus. Loss-of-function Lip mutations are suppressors of position effect variegation (PEV) (Csink et al. 1994), indicating a possible function in gene silencing and heterochromatin formation. This suggested that the persistence of $h s p 70$ and $h s p 83$ transcripts following heat shock might result from a weakened capacity to repress gene transcription, rather than from an alteration in the kinetics of heat-shock recovery induced by the delay in hsp70 export or some other change in RNA stability. If so, the normal turnoff of cellular gene transcription that accompanies heat shock might also be affected.

To help distinguish between these possibilities, we directly compared chromatin structure in control and mutant samples. Active genes can be distinguished by the presence of histone modifications and specific transcription factors. In unstressed wild-type and p68 mutant cells, histone H3 phosphorylation at Ser10 (H3phosS10) generally marked transcriptional activity at many loci scattered throughout the genome, including P11-positive puff sites (Fig. 4A). Upon heat shock, transcription of hsp70 and other response genes depends on direct HSF binding within their promoters, and this binding is accompanied by the accumulation of $\mathrm{H} 3$ phosS10. To probe whether loss of $p 68$ prolongs hsp70 transcription, we ex- amined polytene chromosomes to determine whether $\mathrm{H} 3$ phosS 10 and HSF persist on the $h s p 70$ gene loci longer than normal in p68 CBO2119/LipF mutant animals (Fig. 4B, boxed regions). Immediately following a 20-min heat

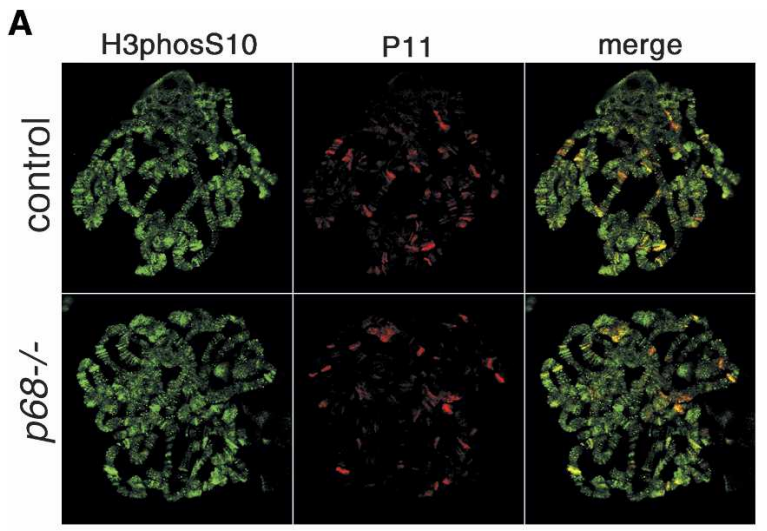

B

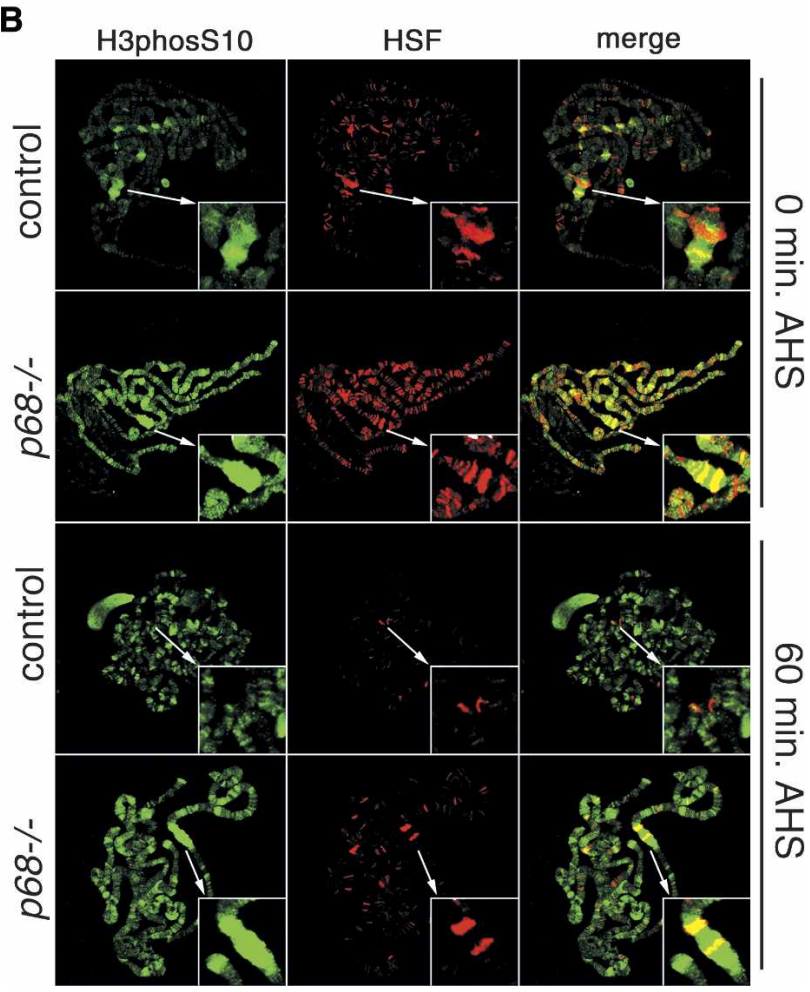

Figure 4. Reduced P68 activity results in persistent transcription factor binding to chromosomes. (A) Control and CB02119/ $\operatorname{Lip}^{F}$ polytene chromosomes from unstressed larvae stained with anti-H3phosS10 and P11 antibodies. (B) Control and CB02119/ Lip $^{F}$ polytene chromosome squashes from larvae heat-shocked for $20 \mathrm{~min}$ and dissected immediately $10 \mathrm{~min}$ AHS) or 60 min AHS. These samples were stained with antiH3phosS10 (green) and anti-HSF (red) antibodies. HSF binding to heat-shock response puffs appears to be comparable in control and mutant samples immediately after heat shock. However, the level and number of sites labeled with the anti$\mathrm{H} 3$ phosS 10 antibody are greater in p68 mutants. While HSF is lost from heat-shock puffs in control samples (control inset) 60 min AHS, HSF binding persists in p68 mutant chromosomes (p68 ${ }^{-/-}$inset). Insets show the hsp70 loci at $87 \mathrm{~A}$ and $87 \mathrm{C}$. 
shock, the $h s p 70$ genes were extensively modified with H3phosS10 and contained abundant HSF in both wildtype and $p 68$ mutant cells. After $1 \mathrm{~h}$ of recovery, both the level of H3phosS10 modification and HSF binding were greatly reduced in wild-type cells. In contrast, high levels of both markers of $h s p 70$ gene activity remained in the p68 mutant animals. Thus, reducing the level of $p 68$ prolongs the accumulation of $\mathrm{H} 3$ phsoS10 and HSF at heatshock loci, further supporting the view that $p 68$ mutation blocks the shutoff of hsp70 transcription.

Further evidence that $p 68$ plays a role in gene deactivation comes from examining the shutdown of endogenous genes following heat shock (Fig. 4B). Immediately after a 20-min heat shock, most previously active genes had shut down in control samples, as measured by the level of H3phosS10 labeling (Fig. 4, cf. B and A). However, after this same time period, p68 ${ }^{\text {CBO2119/LipF }}$ mutant animals continued to display a broad pattern of H3phosS10 labeling. Comparison of banding patterns suggested that many of these were normal loci that had failed to shut off following heat shock. After $1 \mathrm{~h}$ of recovery, H3phosS10 had reappeared at sites throughout the chromosomes in wild type, reflecting the recovery of general transcription (Fig. 4B). The failure to ever lose $\mathrm{H} 3$ phosS 10 at the sites of normally active genes suggests that $p 68$ is not only required to shut down hsp 70 during recovery from heat shock, but is also needed to shut down non-heat-shock genes immediately after the onset of heat shock.

To confirm that the additional loci containing $\mathrm{H} 3$ phosS10 in stressed p68 animals represent sites of active transcription, we examined the distribution of active RNA polymerase II. The large subunit of Pol II is modified by specific serine phosphorylations within its repetitive C-terminal domain (CTD) when active, a change recognized by the $\mathrm{H} 5$ antibody. Following a 20min heat shock of wild-type animals, heat-shock loci were strongly labeled, but H5 reactivity had been lost from most chromosomal sites due to the cessation of general transcription (Fig. 5A,C). In contrast, active Pol II was present in p68 CBO2119/LipH animals at many major and minor sites spread widely along the chromosomes in addition to the heat-shock genes (Fig. 5B,D).

While chromosomal genes clearly retained hallmarks of active transcription following heat shock in p68 mutants, we confirmed their continued activity by analyzing Br-UTP incorporation. Salivary glands from control and p68 mutant larvae were dissected and heat-shocked in culture for $10 \mathrm{~min}$. Br-UTP was then added to the culture, and the glands were kept at $37^{\circ} \mathrm{C}$ for an additional $20 \mathrm{~min}$. The samples were immediately fixed and stained for incorporated Br-UTP (Fig. 5E-H). As expected, control samples showed very little evidence of Br-UTP incorporation except at a few foci that likely correspond to heat-shock gene loci (Fig. 5E,G, arrows). p68 $8^{\mathrm{CBO2119/LipH}}$ mutant animals, on the other hand, incorporated Br-UTP at similar foci, and at multiple additional sites on the chromosomes and in nucleoli (Fig. $5 \mathrm{~F}, \mathrm{H})$. The incorporation of Br-UTP within nucleoli suggests that rRNA genes remain active during stress con- ditions in p68 mutant cells. Thus, many loci not only retain the hallmarks of gene activity in stressed p68 mutants, but continue to synthesize RNA for a prolonged period. All of these assays argue strongly that $p 68$ is required for gene deactivation in addition to its role in RNA export.

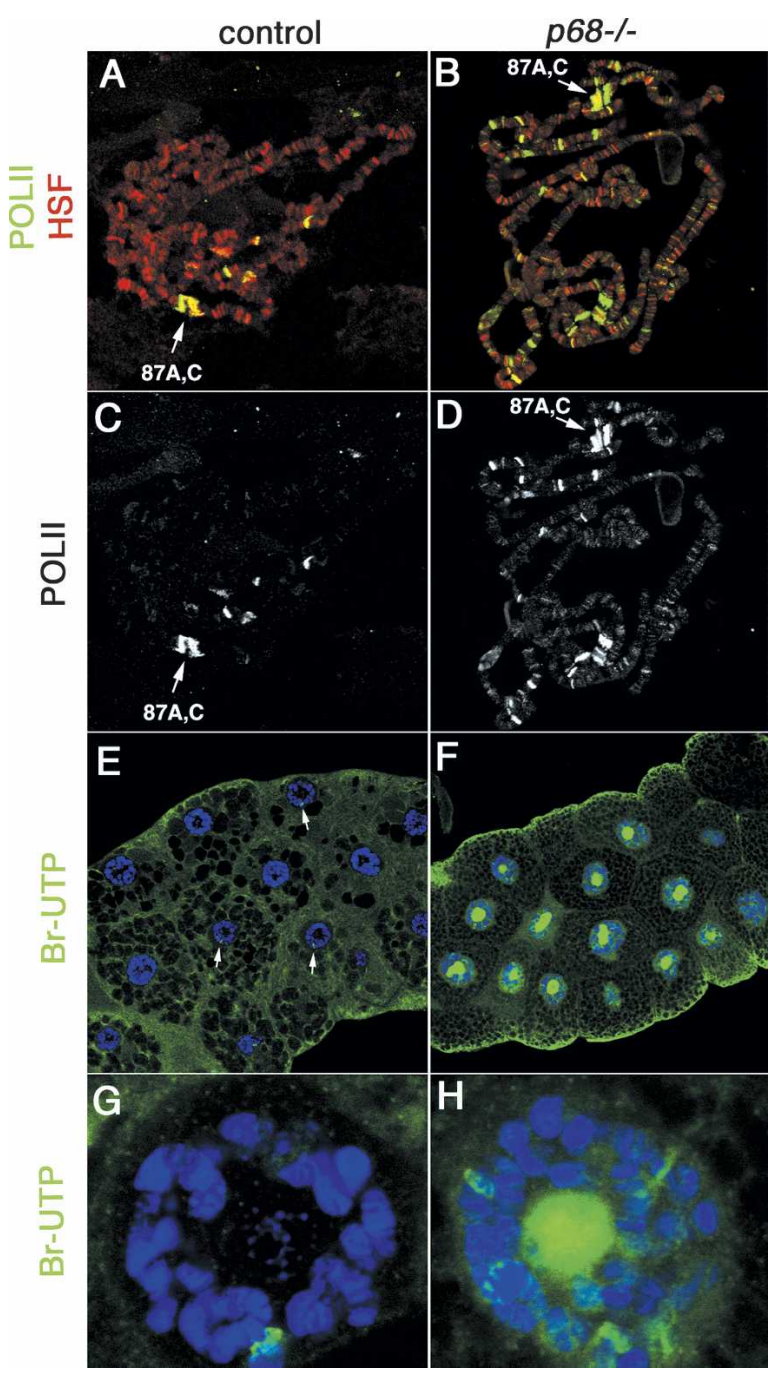

Figure 5. $p 68$ mutation blocks gene shutoff during heat shock. $(A-D)$ Control $(A, C)$ and $C B 02119 / \operatorname{Lip}^{H}(B, D)$ larvae were heatshocked at $37^{\circ} \mathrm{C}$ for $20 \mathrm{~min}$ and immediately processed. The cells were stained using anti-H5 antibodies (green) and anti-HSF antibodies (red) (cf. $C$ and $D$ ). Examining the anti-H5 staining alone reveals that active Pol II is limited to major heat-shock puffs in control cells $(C)$, while in $p 68$ mutant cells, it is present at heat-shock loci, other discrete sites, and generally along chromosome arms $(D)(h s p 70$ gene loci at $87 \mathrm{~A}$ and $87 \mathrm{C}$ are indicated). $(E-F)$ Control $(E, G)$ and CB02119/Lip ${ }^{H}(F, H)$ larvae were heat-shocked at $37^{\circ} \mathrm{C}$ for $10 \mathrm{~min}$, pulse-labeled with Br-UTP, and heat-shocked for an additional $20 \mathrm{~min}$. $(E, G)$ Control samples exhibit Br-UTP labeling only at heat-shock response puffs. $(F, H)$ p68 mutant cells show high levels of Br-UTP incorporation at many chromosomal sites including the nucleolus, demonstrating that a broad number of genes continue to transcribe RNA during heat shock in the absence of $p 68$. 


\section{P68 localizes to genes targeted for repression}

P68 might facilitate gene shutdown simply by continuing to remove completed transcripts, or it might act by a mechanism distinct from its steady-state role in RNA export. If facilitating export was its only role, the level of P68 would not be expected to change dramatically at the time of shutdown. However, if more P68 function was required for gene shutoff, additional P68 might be recruited prior to gene deactivation. To look for evidence of such a change, we studied P68 levels on active heatshock genes and on genes undergoing deactivation after a 30-min heat shock. Before heat shock, P68 and H3phosS10 are both present on several ecdysone puffs and many but not all other secondary loci (Fig. 6, no HS). Frequent colocalization is not surprising given the likely role of P68 in exporting RNA from active loci.

These experiments documented a striking correlation in the level of P68 at the site of hsp70 genes undergoing transcriptional shutdown. As expected, following a 30min heat shock, general H3phosS10 staining was lost and heat-shock loci became strongly labeled (Fig. 6, 0 min AHS). However, despite the fact that the $h s p 70$ genes have already been active for nearly $30 \mathrm{~min}, \mathrm{P} 68$ at this time was still distributed at multiple sites with only very low amounts detectable at the $h s p 70$ loci. These dispersed sites may represent normal genes that have lost H3phosS10 modifications, but are still undergoing P68-mediated deactivation. After $10 \mathrm{~min}$ of recovery, P68 begins to accumulate at high levels at heat-shock loci (Fig. 6, $10 \mathrm{~min}$ AHS). Thirty minutes after heat shock, normal loci (including ecdysone puffs) are beginning to recover based on $\mathrm{H} 3$ phosS10 staining (Fig. 6, 30 min AHS). P68 is now present at even higher levels at the now regressing heat-shock puffs. The dynamic localization patterns suggest that P68 does not simply follow the timing of gene activity, but accumulates at higher levels on loci undergoing gene shutdown. The simplest interpretation of these observations is that the rate of RNA export away from transcription sites increases when a gene is being shut down.

\section{Loss of P68 prolongs ecdysone-responsive gene expression}

The heat-shock response may represent a special case in which the dynamic localization of P68 is required for transcriptional repression. To test whether P68 acts as a specific or general repressor, we looked for other potential targets of $p 68$ regulation. Some $p 68$ transheterozygous mutants remain as third instar larvae for up to $5 \mathrm{~d}$, whereas control animals enter prepupal development after 1-2 d. Delayed molting phenotypes have also been described in mutants that disrupt synthesis and response to the steroid hormone ecdysone (Thummel 1996). Therefore, we tested whether disruption of $p 68$ leads to an alteration in the normal time course of ecdysone-induced gene expression.

Binding of ecdysone to its receptor induces the expression of a set of early response genes that include $E 74$ and E75. Previous results have shown that specific E74 and
E75 isoforms exhibit dynamic expression patterns during late larval and prepupal development (Karim and Thummel 1991, 1992). To test whether P68 regulates the expression of ecdysone-responsive genes, we examined the expression of E74 and E75 during prepupal development.

Total RNA was isolated from control and CB02119/ $\operatorname{Lip}^{F}$ animals at specific time points relative to spiracle eversion. We performed RT-PCR on these samples using primers specific for different isoforms of the $E 74$ and $E 75$ genes (Fig. 7). In control samples, E74B levels are high in wandering larvae, leading up to puparium formation. Once these animals form puparia, the expression of $E 74 B$ gives way to high levels of $E 74 A$ expression within 2-4 h. $E 74 A$ expression then decreases over the next few hours. A similar shutoff of $E 75 B$ also takes place 2-4 h after puparium formation (APF). In $p 68$ mutants, neither $E 74 B$ nor $E 75 B$ shuts off on schedule (Fig. 7). RNA levels of both genes started to decline at least $2 \mathrm{~h}$ later than normal, and unlike controls, complete shutdown is never observed. The decrease in $E 74 A$ expression normally observed by $6 \mathrm{~h}$ after puparium formation in control animals was also delayed and incomplete. E74A RNA did not decline in the $p 68$ mutant animals until $10 \mathrm{~h} \mathrm{APF}$, and remained at higher levels than in the control animals. This experiment confirms that p68-mediated transcriptional regulation is not limited to stress response genes.

\section{Discussion}

P68 is required for transcriptional deactivation

We found that p68 mutant animals turn off genes slowly and incompletely. These include the developmentally regulated early ecdysone response genes E74 and E75, rDNA genes within the nucleolus, and many other active genes that normally cease transcription following heat shock, and the heat-shock response genes themselves during recovery from stress. This prolonged gene activity in p68 mutant animals appears to be normal in regard to chromatin organization, RNA production, and RNA processing. For example, long after hsp 70 genes have shut off in wild-type animals, hsp70 genes in $p 68$ mutants retain high levels of $\mathrm{H} 3$ phosS10 modification, abundant HSF transcription factor, and active RNA polymerase II, and they continue to incorporate Br-UTP into RNA.

Our experiments rule out several potential explanations for the continuing gene activity in $p 68$ mutant animals. First, mammalian P68 has been proposed to facilitate splicing by unwinding base-pairing between the U1 RNA and the 5'-splice junction (Lin et al. 2005). Thus, effects on gene shutdown might be secondary to missplicing of direct shutdown regulators. However, we found no evidence that Drosophila P68 affects splicing. The level of unspliced hsp83 transcripts did not increase beyond a small rise attributable to ongoing transcription, nor could unspliced E74 or E75 gene transcripts be detected in $p 68$ mutants. Genes lacking introns such as hsp70 were affected in the same manner as intron-containing genes. Second, mammalian P68 has been implicated as a direct transcriptional regulator, and may participate in activating p53 target genes (Bates et al. 2005). 


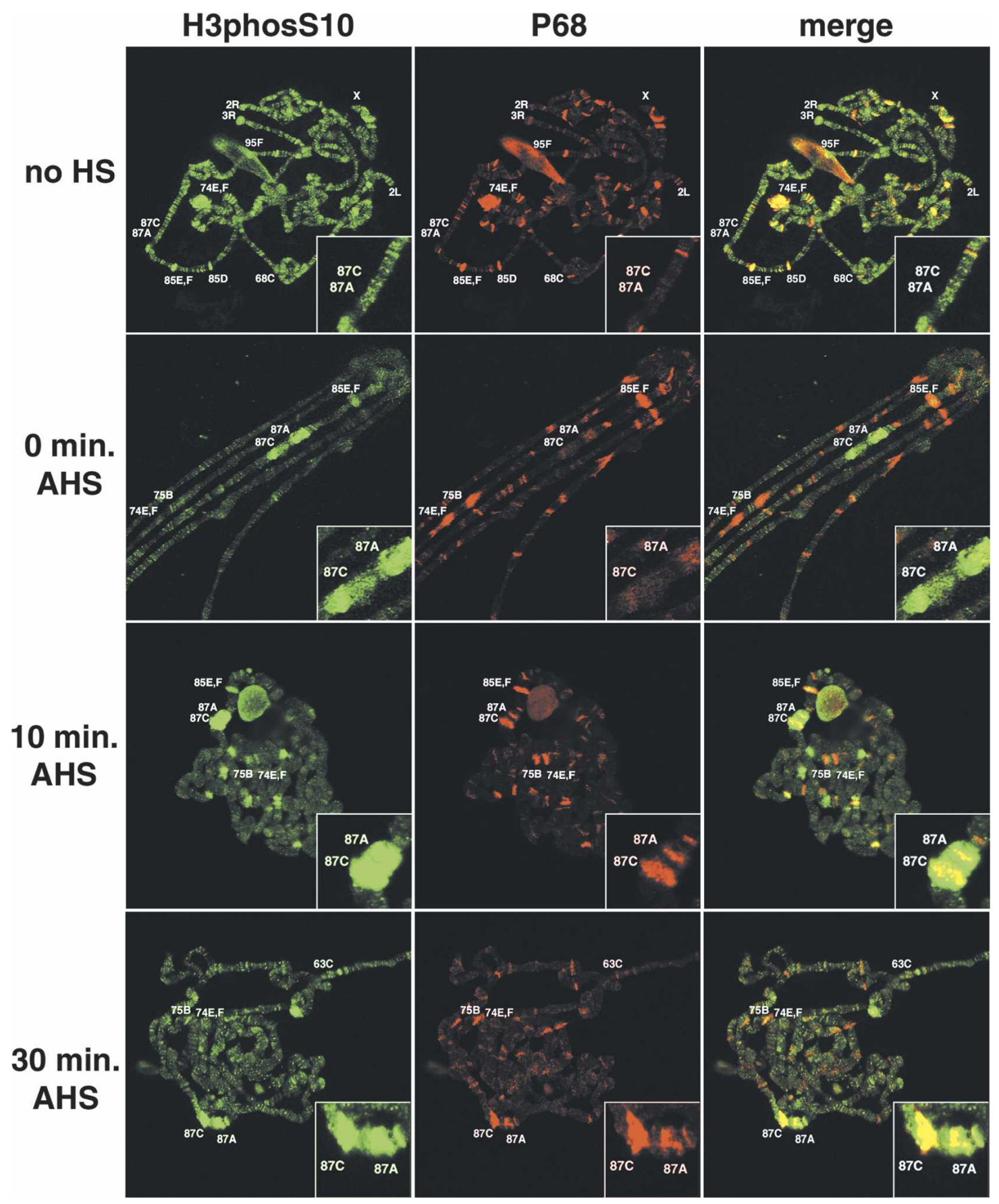

Figure 6. The localization of P68 changes during heat shock. Salivary gland polytene chromosome squashes from wild-type wandering third instar larvae. Samples were unstressed (no HS) or subjected to a 30 -min heat shock at $37^{\circ} \mathrm{C}$ followed by no recovery period (0 min AHS), $10 \mathrm{~min}$ of recovery at room temperature (10 min AHS), and $30 \mathrm{~min}$ of recovery (30 min AHS). Squashes were stained with anti-H3phosS10 and anti-P68 antibodies. Relevant cytological loci are indicated in each panel. In non-heat-shocked animals, there is robust colocalization between $\mathrm{H} 3$ phosS10 and $\mathrm{P} 68$ on a few developmental puffs. Upon heat shock, H3phosS10 accumulates at heat-shock puffs (87A,C) and decreases at other sites (74E,F; 75B). However, P68 remains bound to developmental puffs. After a 10-min recovery period, P68 begins to colocalize with H3phosS10 on heat-shock puffs. This accumulation of P68 on heat-shock puffs continues to increase up to $30 \mathrm{~min}$ after heat shock. Thirty minutes into recovery, H3phosS10 staining begins to accumulate on other bands, while P68 remains highly enriched on heat-shock puffs.

However, Drosophila P68 seems unlikely to act as a transcriptional activator, because the affected genes were diverse and unrelated in function (including the nucleolus), and were up-regulated rather than down-regulated.
A final possibility is that secondary affects of $p 68$ on nuclear physiology feed back and arrest gene shutdown. For example, the delay in HSP70 production caused by p68 mutation might slow the activation of the negative 
A
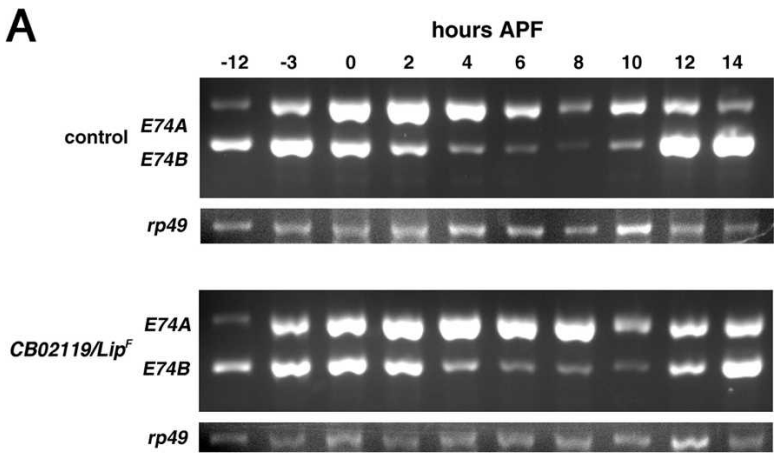

B

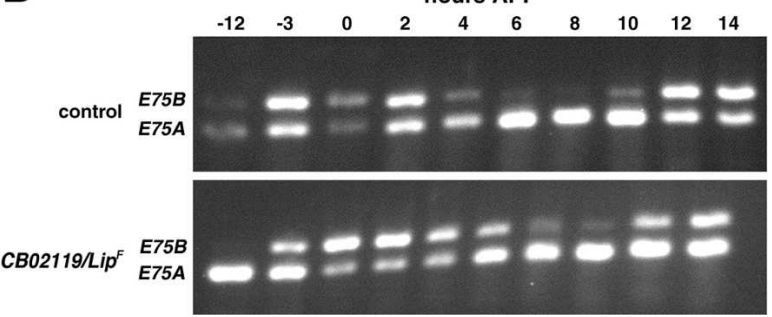

Figure 7. Ecdysone response genes exhibit prolonged expression in the absence of $p 68$. (A) RT-PCR reactions using E74A, $E 74 B$, and $r p 49$ specific primers. Total RNA was isolated from control and $C B 02119 / \mathrm{Lip}^{F}$ animals at the various points after puparium formation. Expression of $E 74 B$ in controls peaks at -3 $\mathrm{h}$ APF and then decreases from 2 to $10 \mathrm{~h} \mathrm{APF}$. A second peak of $E 74 B$ expression is observed beginning at $12 \mathrm{~h}$ APF. E74A expression in control animals first peaks at $2 \mathrm{~h}$ APF and then declines to low levels between 6 and $8 \mathrm{~h} \mathrm{APF}$, followed by a second peak at $10 \mathrm{~h}$ APF that declines rapidly. Mutant animals exhibit prolonged expression of both $E 74 A$ and $E 74 B$ between 2 and $8 \mathrm{~h} \mathrm{APF}$. In addition, the second peak of $E 74 A$ expression never declines in mutant animals over the time course of the experiment. (B) RT-PCR using E75A- and $E 75 B$-specific primers. p68 mutant animals exhibit prolonged expression of both $E 75 A$ and $E 75 B$ relative to the control samples.

feedback loop by which chaperone proteins including HSP70, HSP90, and HSP40 are proposed to normally shut down heat-shock-induced gene expression after removal from stress (Ali et al. 1998; Duina et al. 1998; Shi et al. 1998; Bharadwaj et al. 1999). However, it seems highly unlikely that the diverse genes whose shutdown depends on $p 68$ function, including rDNA genes, ecdysone response genes, and the cellular genes repressed by heat shock, are all subject to such feedback regulation. Instead, the available evidence argues strongly that P68 functions directly in shutting down gene activity, and consistent with such direct action we observed that P68's abundance increases on loci prior to and during the shutdown process.

\section{P68 also functions in RNA clearance from transcription sites}

How, then, does a direct role for P68 in gene shutoff relate to the additional function in RNA export we observed for this molecule? Loss-of-function p68 muta- tions result in bristle and ovary defects similar to those seen in sbr mutants, a known component of the RNA export machinery (Herold et al. 2001, 2003; Wilkie et al. 2001). p68 mutant animals accumulate RNA at transcription sites scattered at many locations around the genome. Furthermore, newly transcribed and processed hsp70 transcripts accumulate at the site of transcription for prolonged periods, causing a pronounced delay in HSP70 translation. These findings suggest that P68 functions at a very early step in RNA export, or at a novel step prior to export that is required to clear completed transcripts from their sites of transcription.

During transcription, various proteins that mediate transcriptional elongation, RNA processing, and RNA export coat nascent transcripts to form large ribonucleoprotein complexes (mRNPs) (Stutz and Izaurralde 2003). Work in a variety of organisms suggests that the assembly of these mRNPs is under strict quality controls. Disruption of RNA processing or association of export factors with transcripts results in RNA accumulation at gene loci and the activation of the RNA surveillance pathway. Defective transcripts are targeted for degradation by the exosome, an evolutionarily conserved multisubunit RNAse complex. The exosome associates with elongation factors and localizes to actively transcribed genes in Drosophila (Andrulis et al. 2002), suggesting that transcripts are constantly monitored for defects. Interestingly, mutations in the rrp $6 p$ exosome gene not only result in the stabilization of RNAs but also lead to their improper release from chromatin (Hilleren et al. 2001). These results suggest that the exosome tethers transcripts to chromatin and ensures that only properly processed RNAs are released for export. P68 may function by interacting with nascent transcripts in a manner that confers competence for a transcript to leave its site of synthesis and undergo transport to nuclear pores. This P68-sensitive step would act as a checkpoint for final release of a completed transcript into the nucleoplasm.

p68-dependent transcript clearance may be required to shut off genes

We favor the idea that P68's requirement for gene shutoff can be explained by its proposed role as a mediator of transcript release. There are two general mechanisms by which nascent transcripts at the site of an active gene might impede transcriptional deactivation. First, some positively acting transcriptional cofactors associate with nascent transcripts rather than remaining at promoter or enhancer regions (Aguilera 2005). Transcript-bound factors would remain at very high local concentrations relative to those that dissociate into the nucleoplasm prior to rebinding. Transcripts bearing such factors would be expected to promote continued gene activity, as part of an equilibrium of positively and negatively acting mechanisms that determine the instantaneous rate of transcriptional activity. During repression, up-regulated RNA release mediated by P68 would lower the local concentration of such factors and help shift the equilibrium toward a state that favors gene deactivation. 
Gene activity is also controlled by the state of chromatin decondensation (for review, see Jenuwein and Allis 2001). Decondensation is correlated with high levels of histone acetylation (Jenuwein and Allis 2001), phosphorylation (Nowak and Corces 2004), and ADP-ribose modification (Tulin et al. 2003), and these modifications must be reversed to complete gene shutoff. The presence of bulky mRNPs around a gene might simply block chromatin from reassembling into the highly compact state characteristic of inactive genes. Transcripts and their associated protein complexes might also be inhibitory to chromatin-remodeling processes due to specific proteinprotein interactions. The targeting of extra P68 to genes at the onset of gene shutdown might stimulate export of the remaining transcripts that would counteract the repression process.

Multiple genes within a chromosome region are sometimes shut down coordinately through the process of heterochromatin formation. The ability of $p 68$ to stimulate gene deactivation via transcript release may play a role in forming heterochromatin as well as in shutting off individual genes, because p68/Lip was previously identified as a suppressor of position effect variegation (Csink et al. 1994). This suggests that transcript removal may be an important part of heterochromatin formation and spreading. The RNAi pathway has been shown to facilitate heterochromatic silencing (Bernstein and Allis 2005). Drosophila P68 has been found in a complex with Argonaute2, suggesting that it might directly interact with the RNAi machinery (Ishizuka et al. 2002). There may be a mechanistic link between the function of P68 in transcript clearance and of the RNAi pathway in promoting gene silencing.

\section{Materials and methods}

\section{Fly strains and genetics}

Fly stocks were maintained at $20^{\circ} \mathrm{C}-23^{\circ} \mathrm{C}$ on standard cornmeal-agar-yeast food. The y $W$ strain used for generating CB02119 was used as a control in all experiments. CB02119 was generated by mobilizing the GFP-trapping P-element described in Morin et al. (2001). 1(3)01084 is described in Spradling et al. (1999), and $\operatorname{Lip}^{E}, \operatorname{Lip}^{F}, \operatorname{Lip}^{H}$, and $\operatorname{Lip}^{K}$ are described in Csink et al. (1994).

\section{P68 antibody production}

The sequence corresponding to the first 147 amino acids of P68$\mathrm{RB}$ was cloned into a modified pPRO-EXHTC (Invitrogen) vector (gift from J. Wilhelm, Carnegie Institution of Washington, Baltimore, MD) using a LR clonase reaction (Invitrogen) following the manufacturer's protocol. This bacterial expression vector places a 6xHIS tag at the $\mathrm{N}$ terminus of the ORF. Expression of this construct in a large-scale culture was induced using 0.2 mM IPTG for $4 \mathrm{~h}$. Cells were then lysed in $6 \mathrm{M}$ guanidine and incubated with Ni-beads (Qiagen). These beads were then washed into $6 \mathrm{M}$ urea, and P68 recombinant protein was eluted off the beads using $300 \mathrm{mM}$ imidazole in $6 \mathrm{M}$ urea. Various elution fractions were run on $10 \%$ SDS-PAGE gels and stained with Coomassie blue to check for purity. Antibodies against recombinant P68 protein were generated in guinea pigs by Covance Research Products.
RNA in situ and Br-UTP labeling

FISH using DIG-labeled hsp70 antisense probes was performed on salivary glands as described in Franke and Baker (1999). The DIG-labeled RNA was detected using sheep anti-DIG antibodies (1:2000; Roche) and anti-sheep Alexa 568 antibodies (1:200; Molecular Probes). A final concentration of 2 mM Br-UTP (Sigma) was used to pulse-label nascent RNA in salivary glands. BrUTP-labeled RNA was detected using rat anti-BrdU antibodies (1:50; Serotec).

\section{Immunostaining and polytene chromosome squashes}

Whole-mount samples were fixed with $4 \%$ paraformaldehyde for $10 \mathrm{~min}$ and processed using standard procedures. Squashes of third instar larval salivary glands were performed as described in Paro (2000) with the following modifications: Samples were dissected in $1 \times$ PBS, $0.1 \%$ Triton X-100, and the glands were then fixed in $4 \%$ paraformaldehyde, $50 \%$ acetic acid, $1 \%$ Triton $\mathrm{X}-100$ for 2 min and squashed in $45 \%$ acetic acid.

Primary antibodies were diluted in PBT $(1 \times$ PBS, $0.3 \%$ Triton $\mathrm{X}-100,0.5 \% \mathrm{BSA}$ ) and used at the following dilutions: rabbit anti-GFP (1:2000; Torrey Pines Biolabs); guinea pig anti-P68 (1:500); mouse anti-Hrb87 (1:50; kind gift from H. Saumweber, Institut für Biologie, Berlin, Germany); rabbit anti-H3phosS10 (Upstate); anti-HSF (1:50; kind gift from J. Lis, Cornell University, Ithaca, NY); anti-NXF1 (1:100; kind gift from E. Izaurralde, European Molecular Biology Laboratory, Heidelberg, Germany), anti-REF1 (1:100; kind gift from E. Izaurralde; and mouse antiAJ1 (1:20; kind gift from J. Gall, Carnegie Institution of Washington, Baltimore, MD). The following secondary antibodies were used: goat anti-rabbit, goat anti-mouse, or goat anti-guinea pig conjugated to either Alexa 488 or Alexa 568 (1:200; Molecular Probes).

\section{Western blot analysis}

Standard Western blotting techniques were used. Ponceau S staining of membranes was used to confirm equal loading between lanes immediately after transfer. Antibodies were used at the following concentrations: guinea pig anti-P68 (1:3000), mouse anti-Actin (1:200), mouse anti-HSP70 (1:1000), goat antimouse HRP (1:2000; Jackson Labs), goat anti-rabbit HRP (1:2000; Jackson Labs), and goat anti-guinea pig-HRP (1:2000; Jackson Labs).

\section{Northern blot}

Total RNA was isolated using Trizol reagent (Invitrogen) and fractionated on a $1 \%$ formaldehyde-agarose gel. The gel was soaked in $0.05 \mathrm{~N} \mathrm{NaOH}$ for $10 \mathrm{~min}$ and washed in $\mathrm{dH}_{2} \mathrm{O}$. RNA was transferred to a nitrocellulose membrane using 10× SSPE and then cross-linked with a UV-Stratalinker. Membranes were then prehybridized with DIG Easy Hyb Granules (Roche) for 30 min at $65^{\circ} \mathrm{C}$ and then hybridized with DIG-labeled $h s p 70$ and rp49 RNA antisense probes overnight at $65^{\circ} \mathrm{C}$. The membrane was then washed in Post-Hybridization washes: two times for 5 $\min$ in $2 \times \mathrm{SSC}$; SDS $(0.1 \%)$ at $15^{\circ} \mathrm{C}-25^{\circ} \mathrm{C}$ followed by two times for $15 \mathrm{~min}$ in $0.5 \times \mathrm{SSC}$; SDS $(0.1 \%)$ at $65^{\circ} \mathrm{C}$ under constant agitation. The membrane was incubated for $30 \mathrm{~min}$ in blocking solution ( $1 \%$ blocking reagent [Roche] in $0.1 \mathrm{M}$ maleic acid at $\mathrm{pH} 7.4,0.15 \mathrm{M} \mathrm{NaCl}$ ), followed by a 30-min incubation with sheep anti-DIG-AP (Roche) in blocking solution. The membrane was then washed extensively, soaked with CDP-Star reagent (Roche), and exposed to film. 


\section{RT-TAIL-PCR and RT-PCR}

The insertion site of CB02119 was originally determined using an inverse PCR protocol (Bellen et al. 2004). To confirm that CB02119 trapped $p 68$, an $\mathrm{RT}$ reaction was coupled to a modified TAIL-PCR reaction (Singer and Burke 2003). Briefly, total RNA was isolated from 13 adult flies using a 96-well RNAqueous kit (Ambion) following the manufacturer's protocol. Five microliters of total RNA was used in a 50- $\mu \mathrm{L}$ RT reaction using Qiagen's One Step RT-PCR kit following the manufacturer's protocol. This same reaction was then subjected to three rounds of TAIL-PCR, using the following GFP-specific primers: GFPFor1， 5'-GGAGGACGGCAACATCCTGG-3'; GFP-For2， 5'CAACGTCTATATCATGGCCG-3'; GFP-For3, 5'-AGACCCC AACGAGAAGCGCG-3'; GFP-Rev1， 5'-GTCGTGCTGCTT CATGTGGTCG-3'; GFP-Rev2， 5'-GACACGCTGAACTTGT GGCCG-3'; GFP-Rev3, 5'-AGCTCCTCGCCCTTGCTCACC$3^{\prime}$. The resulting products were then sequenced.

For E74 and E75 RT-PCR reactions, control and CB02119/ $\mathrm{Lip}^{H}$ samples were staged as previously described except that slow wandering larvae were used for the -3 -h time point, and fast crawling larvae were used for the -12 -h time point. Total RNA from these samples was isolated using Trizol reagent according to the manufacturer's instructions. Equal amounts of RNA were used in a One Step RT-PCR reaction (Qiagen) using $E 74$ and $E 75$ isoform-specific primers as described in Huet et al. (1993). rp49 primers were included in the $E 74$ reactions, and the resulting RT-PCR product served as a control. Products were run on a $2 \%$ agarose gel.

\section{Acknowledgments}

We thank John Lis, Jim Wilhelm, H. Saumweber, J. Birchler, E. Izaurralde, and I. Davis for antibodies and fly stocks. We thank Mike Sepanski for assistance with electron microscopy. Jim Wilhelm, Judy Yanowitz, Ben Ohlstein, and Yixian Zheng provided valuable comments on the manuscript. M.B. is supported by American Cancer Society Post-doctoral Fellowship Grant \#PF-04-022-01-CSM.

\section{References}

Adelman, K., Marr, M.T., Werner, J., Saunders, A., Ni, Z., Andrulis, E.D., and Lis, J.T. 2005. Efficient release from promoter-proximal stall sites requires transcript cleavage factor TFIIS. Mol. Cell 17: 103-112.

Aguilera, A. 2005. Cotranscriptional mRNP assembly: From the DNA to the nuclear pore. Curr. Opin. Cell Biol. 17: 242-250.

Ali, A., Bharadwaj, S., O'Carroll, R., and Ovsenek, N. 1998. HSP90 interacts with and regulates the activity of heat shock factor 1 in Xenopus oocytes. Mol. Cell. Biol. 18: 49494960.

Andrulis, E.D., Guzman, E., Doring, P., Werner, J., and Lis, J.T. 2000. High-resolution localization of Drosophila Spt5 and Spt6 at heat shock genes in vivo: Roles in promoter proximal pausing and transcription elongation. Genes \& Dev. 14: 2635-2649.

Andrulis, E.D., Werner, J., Nazarian, A., Erdjument-Bromage, H., Tempst, P., and Lis, J.T. 2002. The RNA processing exosome is linked to elongating RNA polymerase II in Drosophila. Nature 420: 837-841.

Bates, G.J., Nicol, S.M., Wilson, B.J., Jacobs, A.M., Bourdon, J.C., Wardrop, J., Gregory, D.J., Lane, D.P., Perkins, N.D., and Fuller-Pace, F.V. 2005. The DEAD box protein p68: A novel transcriptional coactivator of the p53 tumour suppressor. EMBO J. 24: 543-553.
Bellen, H.J., Levis, R.W., Liao, G., He, Y., Carlson, J.W., Tsang, G., Evans-Holm, M., Hiesinger, P.R., Schulze, K.L., Rubin, G.M., et al. 2004. The BDGP gene disruption project: Single transposon insertions associated with $40 \%$ of Drosophila genes. Genetics 167: 761-781.

Bernstein, E. and Allis, C.D. 2005. RNA meets chromatin. Genes \& Dev. 19: 1635-1655.

Bharadwaj, S., Ali, A., and Ovsenek, N. 1999. Multiple components of the HSP90 chaperone complex function in regulation of heat shock factor 1 in vivo. Mol. Cell. Biol. 19: 8033-8041.

Csink, A.K., Linsk, R., and Birchler, J.A. 1994. The Lighten up (Lip) gene of Drosophila melanogaster, a modifier of retroelement expression, position effect variegation and white locus insertion alleles. Genetics 138: 153-163.

Dej, K.J. and Spradling, A.C. 1999. The endocycle controls nurse cell polytene chromosome structure during Drosophila oogenesis. Development 126: 293-303.

DiDomenico, B.J., Bugaisky, G.E., and Lindquist, S. 1982a. Heat shock and recovery are mediated by different translational mechanisms. Proc. Natl. Acad. Sci. 79: 6181-6185.

- 1982b. The heat shock response is self-regulated at both the transcriptional and posttranscriptional levels. Cell 31: 593-603.

Duina, A.A., Kalton, H.M., and Gaber, R.F. 1998. Requirement for Hsp90 and a CyP-40-type cyclophilin in negative regulation of the heat shock response. J. Biol. Chem. 273: 18974-18978.

Estruch, F. and Cole, C.N. 2003. An early function during transcription for the yeast mRNA export factor Dbp5p/Rat8p suggested by its genetic and physical interactions with transcription factor IIH components. Mol. Biol. Cell 14: 1664-1676.

Fasken, M.B. and Corbett, A.H. 2005. Process or perish: Quality control in mRNA biogenesis. Nat. Struct. Mol. Biol. 12: 482-488.

Franke, A. and Baker, B.S. 1999. The rox 1 and rox 2 RNAs are essential components of the compensasome, which mediates dosage compensation in Drosophila. Mol. Cell 4: 117-122.

Gatfield, D. and Izaurralde, E. 2002. REF1/Aly and the additional exon junction complex proteins are dispensable for nuclear mRNA export. J. Cell Biol. 159: 579-588.

Gatfield, D., Le Hir, H., Schmitt, C., Braun, I.C., Kocher, T., Wilm, M., and Izaurralde, E. 2001. The DExH/D box protein HEL/UAP56 is essential for mRNA nuclear export in Drosophila. Curr. Biol. 11: 1716-1721.

Golubkova, E.V., Pugacheva, O.M., Demina, E.P., Musorina, A.S., Shershabova, A.N., and Mamon, L.A. 2004. Sterilizing effect of the mutant allele sbr10 (1(1)ts403) in compound with null alleles in Drosophila melanogaster females. Genetika 40: 469-477.

Henikoff, S. and Ahmad, K. 2005. Assembly of variant histones into chromatin. Annu. Rev. Cell Dev. Biol. 21: 133-153.

Herold, A., Klymenko, T., and Izaurralde, E. 2001. NXF1/p15 heterodimers are essential for mRNA nuclear export in Drosophila. RNA 7: 1768-1780.

Herold, A., Teixeira, L., and Izaurralde, E. 2003. Genome-wide analysis of nuclear mRNA export pathways in Drosophila. EMBO I. 22: 2472-2483.

Hilleren, P., McCarthy, T., Rosbash, M., Parker, R., and Jensen, T.H. 2001. Quality control of mRNA 3'-end processing is linked to the nuclear exosome. Nature 413: 538-542.

Huang, Y. and Liu, Z.R. 2002. The ATPase, RNA unwinding, and RNA binding activities of recombinant p68 RNA helicase. J. Biol. Chem. 277: 12810-12815.

Huertas, P. and Aguilera, A. 2003. Cotranscriptionally formed DNA:RNA hybrids mediate transcription elongation impairment and transcription-associated recombination. Mol. Cell 12: 711-721.

Huet, F., Ruiz, C., and Richards, G. 1993. Puffs and PCR: The in 
vivo dynamics of early gene expression during ecdysone responses in Drosophila. Development 118: 613-627.

Ishizuka, A., Siomi, M.C., and Siomi, H. 2002. A Drosophila fragile $\mathrm{X}$ protein interacts with components of RNAi and ribosomal proteins. Genes \& Dev. 16: 2497-2508.

Jankowsky, E., Gross, C.H., Shuman, S., and Pyle, A.M. 2001. Active disruption of an RNA-protein interaction by a DExH/D RNA helicase. Science 291: 121-125.

Jensen, T.H., Patricio, K., McCarthy, T., and Rosbash, M. 2001. A block to mRNA nuclear export in $S$. cerevisiae leads to hyperadenylation of transcripts that accumulate at the site of transcription. Mol. Cell 7: 887-898.

Jenuwein, T. and Allis, C.D. 2001. Translating the histone code. Science 293: 1074-1080.

Jimeno, S., Rondon, A.G., Luna, R., and Aguilera, A. 2002. The yeast THO complex and mRNA export factors link RNA metabolism with transcription and genome instability. EMBO I. 21: 3526-3535.

Karim, F.D. and Thummel, C.S. 1991. Ecdysone coordinates the timing and amounts of E74A and E74B transcription in Drosophila. Genes \& Dev. 5: 1067-1079.

- 1992. Temporal coordination of regulatory gene expression by the steroid hormone ecdysone. EMBO J. 11: 40834093.

Kwek, K.Y., Murphy, S., Furger, A., Thomas, B., O'Gorman, W., Kimura, H., Proudfoot, N.J., and Akoulitchev, A. 2002. U1 snRNA associates with TFIIH and regulates transcriptional initiation. Nat. Struct. Biol. 9: 800-805.

Lin, C., Yang, L., Yang, J.J., Huang, Y., and Liu, Z.R. 2005. ATPase/helicase activities of p68 RNA helicase are required for pre-mRNA splicing but not for assembly of the spliceosome. Mol. Cell. Biol. 25: 7484-7493.

Manley, J.L. 2002. Nuclear coupling: RNA processing reaches back to transcription. Nat. Struct. Biol. 9: 790-791.

Mohr, S.E., Dillon, S.T., and Boswell, R.E. 2001. The RNA-binding protein Tsunagi interacts with Mago Nashi to establish polarity and localize oskar mRNA during Drosophila oogenesis. Genes \& Dev. 15: 2886-2899.

Morin, X., Daneman, R., Zavortink, M., and Chia, W. 2001. A protein trap strategy to detect GFP-tagged proteins expressed from their endogenous loci in Drosophila. Proc. Natl. Acad. Sci. 98: 15050-15055.

Nowak, S.J. and Corces, V.G. 2000. Phosphorylation of histone H3 correlates with transcriptionally active loci. Genes \& Dev. 14: 3003-3013.

- 2004. Phosphorylation of histone H3: A balancing act between chromosome condensation and transcriptional activation. Trends Genet. 20: 214-220.

Paro, R. 2000. Mapping protein distributions on polytene chromosomes by immunostaining. In Drosophila protocols (eds. W. Sullivan et al.), pp. 131-139. Cold Spring Harbor Laboratory Press, Cold Spring Harbor, NY.

Pause, A. and Sonenberg, N. 1992. Mutational analysis of a DEAD box RNA helicase: The mammalian translation initiation factor eIF-4A. EMBO J. 11: 2643-2654.

Reed, R. 2003. Coupling transcription, splicing and mRNA export. Curr. Opin. Cell Biol. 15: 326-331.

Rehwinkel, J., Herold, A., Gari, K., Kocher, T., Rode, M., Ciccarelli, F.L., Wilm, M., and Izaurralde, E. 2004. Genomewide analysis of mRNAs regulated by the THO complex in Drosophila melanogaster. Nat. Struct. Mol. Biol. 11: 558-566.

Reim, I., Mattow, J., and Saumweber, H. 1999. The RRM protein NonA from Drosophila forms a complex with the RRM proteins Hrb87F and S5 and the Zn finger protein PEP on hnRNA. Exp. Cell Res. 253: 573-586.
Rocak, S. and Linder, P. 2004. DEAD-box proteins: The driving forces behind RNA metabolism. Nat. Rev. Mol. Cell Biol. 5: 232-241.

Rodrigues, J.P., Rode, M., Gatfield, D., Blencowe, B.J., CarmoFonseca, M., and Izaurralde, E. 2001. REF proteins mediate the export of spliced and unspliced mRNAs from the nucleus. Proc. Nat1. Acad. Sci. 98: 1030-1035.

Rodriguez-Navarro, S., Fischer, T., Luo, M.J., Antunez, O. Brettschneider, S., Lechner, J., Perez-Ortin, J.E., Reed, R., and Hurt, E. 2004. Sus1, a functional component of the SAGA histone acetylase complex and the nuclear pore-associated mRNA export machinery. Cell 116: 75-86.

Shi, Y., Mosser, D.D., and Morimoto, R.I. 1998. Molecular chaperones as HSF1-specific transcriptional repressors. Genes \& Dev. 12: 654-666.

Singer, T. and Burke, E. 2003. High-throughput TAIL-PCR as a tool to identify DNA flanking insertions. Methods Mol. Biol. 236: 241-272.

Smith, S.T., Petruk, S., Sedkov, Y., Cho, E., Tillib, S., Canaani, E., and Mazo, A. 2004. Modulation of heat shock gene expression by the TAC1 chromatin-modifying complex. Nat. Cell Biol. 6: 162-167.

Spradling, A.C., Stern, D., Beaton, A., Rhem, E.J., Laverty, T., Mozden, N., Misra, S., and Rubin, G.M. 1999. The Berkeley Drosophila genome project gene disruption project: Single P-element insertions mutating $25 \%$ of vital Drosophila genes. Genetics 153: 135-177.

Strasser, K., Masuda, S., Mason, P., Pfannstiel, J., Oppizzi, M., Rodriguez-Navarro, S., Rondon, A.G., Aguilera, A., Struhl, K., Reed, R., et al. 2002. TREX is a conserved complex coupling transcription with messenger RNA export. Nature 417: 304-308.

Stutz, F. and Izaurralde, E. 2003. The interplay of nuclear mRNP assembly, mRNA surveillance and export. Trends Cell Biol. 13: 319-327.

Thummel, C.S. 1996. Flies on steroids-Drosophila metamorphosis and the mechanisms of steroid hormone action. Trends Genet. 12: 306-310.

Tulin, A. and Spradling, A. 2003. Chromatin loosening by poly(ADP)-ribose polymerase (PARP) at Drosophila puff loci. Science 299: 560-562.

Tulin, A., Chinenov, Y., and Spradling, A. 2003. Regulation of chromatin structure and gene activity by poly(ADP-ribose) polymerases. Curr. Top. Dev. Biol. 56: 55-83.

Vinciguerra, P. and Stutz, F. 2004. mRNA export: An assembly line from genes to nuclear pores. Curr. Opin. Cell Biol. 16: 285-292.

Westwood, J.T. and Wu, C. 1993. Activation of Drosophila heat shock factor: Conformational change associated with a monomer-to-trimer transition. Mol. Cell. Biol. 13: 3481-3486.

Wilkie, G.S., Zimyanin, V., Kirby, R., Korey, C., Francis-Lang, H., Van Vactor, D., and Davis, I. 2001. Small bristles, the Drosophila ortholog of NXF-1, is essential for mRNA export throughout development. RNA 7: 1781-1792.

Wilson, B.J., Bates, G.J., Nicol, S.M., Gregory, D.J., Perkins, N.D., and Fuller-Pace, F.V. 2004. The p68 and p72 DEAD box RNA helicases interact with HDAC1 and repress transcription in a promoter-specific manner. BMC Mol. Biol. 5: 11.

Wu, C., Wilson, S., Walker, B., Dawid, I., Paisley, T., Zimarino, V., and Ueda, H. 1987. Purification and properties of Drosophila heat shock activator protein. Science 238: $1247-1253$. 


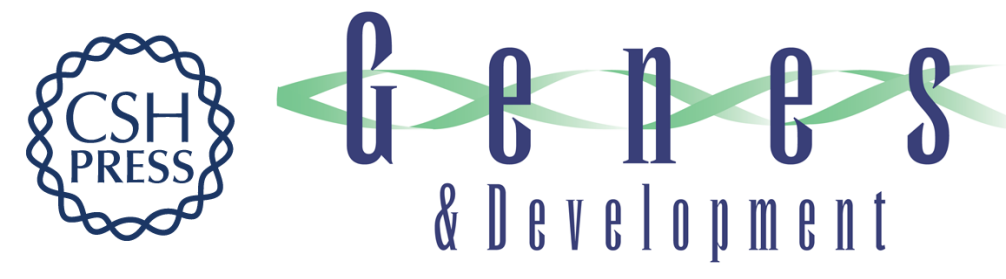

\section{The Drosophila P68 RNA helicase regulates transcriptional deactivation by promoting RNA release from chromatin}

Michael Buszczak and Allan C. Spradling

Genes Dev. 2006, 20:

Access the most recent version at doi:10.1101/gad.1396306

References This article cites 62 articles, 31 of which can be accessed free at: http://genesdev.cshlp.org/content/20/8/977.full.html\#ref-list-1

License

Email Alerting Receive free email alerts when new articles cite this article - sign up in the box at the top Service right corner of the article or click here.

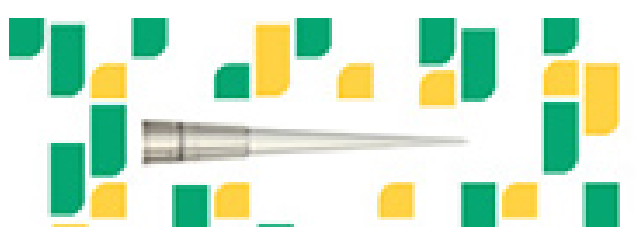

Focused on your science. 